\title{
O trabalho docente na escola de massa: desafios e perspectivas
}

ISABEL LELIS*

\section{Resumo}

Este artigo tem como eixo central o trabalho dos professores na escola de massa, hoje. Em um primeiro momento, foram trazidas questões presentes na literatura internacional e nacional, reveladoras dos desafios que se colocam aos docentes, como a intensificação e complexificação da profissão, a diversificação das tarefas docentes em função de um conjunto de transformações sociais, a importância que adquire a formação de professores, tendo em vista a busca pela efetividade do ensino. Em função da magnitude desses problemas, análises da Organização de Cooperação e Desenvolvimento Econômico (OCDE) e da Comunidade Europeia foram incorporadas ao texto, dada a centralidade que assumiu o campo das políticas de formação de professores para os países-membros desses organismos. A última parte do texto tem a preocupação de analisar os principais problemas enfrentados pelo magistério no contexto brasileiro, como a sobrecarga de trabalho, o esgotamento crescente que vem acometendo os professores e as dificuldades que enfrentam de atualização profissional, já identificadas na produção acadêmica.

Palavras-chave: Escola de massa. Trabalho docente. Formação de professores. Magistério do Brasil

\footnotetext{
* Professora e pesquisadora do Programa de Pós-Graduação em Educação da Pontifícia Universidade Católica do Rio de Janeiro (Brasil). Coordenadora do GEPPE - Grupo de Estudos e Pesquisas sobre o Professor e o Ensino. E-mail: isabell@puc-rio.br
} 


\section{Teaching in large classes: challenges and perspectives}

\section{Abstract}

The main focus of this paper is the teaching conditions in large classes today. Initially the text sheds light on aspects brought up in the international and Brazilian literature that reveal the challenges of teaching profession, such as the increased working hours and complexity of profession, diversification of tasks in association with social transformations, and the crucial role of teacher's education and training for achieving teaching effectiveness. In view of the magnitude of such issues, it was also taken into account studies done by the Organization for Economic Co-operation and Development (OECD) and by European Community, because of the increased attention given to public policies for teaching and learning conditions. The final part of this study analyzes the main problems of teaching in Brazil approached in the reviewed literature, such as the work overload, the so-called burn-out effect that affects an increasing number of teachers and the difficulties of continuing education.

Keywords: Teaching large classes. Teaching work. Teacher training. Teaching in Brazil

\section{Introdução}

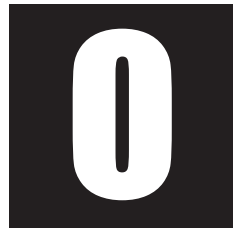

$\mathrm{m}$ recente texto sobre o significado de ser professor na escola de massa, Formosinho (2009) aponta para o fato de que a escola de massa é essencialmente heterogênea, seja do ponto de vista dos professores, seja do ponto de vista dos alunos e do contexto geográfico e social de inserção das escolas.

Para esse autor, com a explosão escolar, a necessidade de mais professores provocou um rebaixamento das exigências de entrada na profissão, passando a coexistirem professores com titulações muito diferentes do ponto de vista da formação acadêmica, oriundos de estabelecimentos de 
ensino diversos. A necessidade de prover as escolas rapidamente de docentes levou à criação de esquemas de facilitação de acesso dos docentes sem a qualificação necessária. Como era de se esperar a degradação da imagem social do professor e da autoimagem profissional foi uma consequência inevitável (Formosinho, 2006, p.43). E, continua o autor, o alargamento da rede escolar produziu um quadro bastante desafiador, uma vez que:

Há escolas em zonas rurais, em vilas, em zonas suburbanas e em zonas urbanas. Nestas há escolas no centro e em bairros, em zonas residenciais da classe média e em zonas degradadas. Como é evidente, esta heterogeneidade de contextos reflete-se na composição discente da escola e, indiretamente, na composição docente (Formosinho, 2006, p. 43)

Esse alargamento de rede escolar traz um outro fenômeno: o professor que dá aulas na escola muitas vezes não é membro da comunidade geográfica. Para esse autor, essa não fixação dos professores, conjuntamente com a sua extrema mobilidade de escola para escola, põe novos problemas à relação do corpo docente e da escola com o bairro e a população local (Formosinho, 2009, p. 44).

Se essas questões referem-se às configurações da escola de massa em Portugal, quando passamos a pensar no caso do Brasil, nosso sistema de ensino guarda também diferenças grandes pela extrema desigualdade na qualidade da oferta escolar, dos processos de escolarização, das condições de trabalho do professor.

Elegendo como objeto de estudo a problemática da profissão docente hoje no Brasil, nosso primeiro movimento, para efeito deste texto, foi o de trazer as principais questões que cercam essa problemática do ponto de vista da literatura internacional e nacional. Em que pesem as diferenças de abordagem teórico-metodológica, alguns temas foram recorrentes na revisão efetuada, como, por exemplo, a ampliação das tarefas do professor, a diversificação do papel do professor, a preocupação com 
o desenvolvimento profissional desses agentes com vistas à melhoria dos processos de ensino-aprendizagem.

Merece destaque, na produção acadêmica analisada, a crítica à formação de professores pela sua distância em relação ao mundo da sala de aula, crítica essa traduzida por Nóvoa (2008) na seguinte afirmação: "é preciso trazer a formação para dentro da profissão", em uma clara alusão à necessidade das práticas de formação ocorrerem em contexto de trabalho. Mas para além dessa crítica, há uma preocupação com a eficácia do professor, e, portanto, de novos paradigmas que devem nortear as políticas e os processos de formação docente.

Do ponto de vista da estrutura do texto, a primeira seção trata da intensificação do trabalho docente, especialmente na gestão da sala de aula, exigindo o desenvolvimento de competências para além do domínio de conhecimentos e habilidades. A segunda parte debruça-se sobre as demandas sociais colocadas para a escola (formação para a cidadania, instrução, qualificação para o mercado de trabalho, entre outras) com impacto no papel tradicionalmente exercido pelos professores. A terceira seção elege como foco a importância crescente do desenvolvimento profissional dos professores, tendo em vista a melhoria do ensino, importância essa ampliada a partir das políticas de avaliação dos sistemas escolares. Por fim, na última parte, foram analisados os principais desafios colocados ao trabalho dos professores no Brasil hoje. Entre os problemas mapeados, destaca-se o mal-estar profissional provocado pela sobrecarga de trabaIho, pelo esgotamento (síndrome de burnout), pelos baixos salários, pelas dificuldades de atualização profissional.

\section{Intensificação do trabalho docente}

Assistimos na última década a um esforço crescente dos pesquisadores em mapear a problemática da profissão docente. Em comum, existe 
a percepção de que o trabalho do professor se caracteriza hoje pela intensificação e complexificação do próprio trabalho (Maroy, 2006). Com relação ao primeiro aspecto, não se trata apenas de aumento de tempo do trabalho, mas também da ampliação das tarefas a que os professores são chamados a desempenhar, seja pelas mudanças na composição social do público escolar, seja pela implementação de reformas educacionais com visíveis impactos no cotidiano do trabalho em sala de aula.

Se tomarmos especificamente, por exemplo, o tempo de trabalho, a literatura internacional vem chamando a atenção para a ampliação do número de horas comparativamente a outras categorias profissionais em função da diversificação das atividades dos professores (Tardif e Lessard, 1999). Em pesquisas realizadas no Canadá, estima-se que o tempo varie em torno de trinta e sete a quarenta horas semanais, sendo vinte e sete obrigatoriamente na escola e cinco a oito horas usadas em casa com tarefas de planejamento e correção das tarefas. O tempo que resta é ocupado com reuniões com pais, atividades de formação (op.cit). Apesar da dificuldade de estimar e comparar o tempo de trabalho dos professores de um país para o outro, do ponto de vista do estatutariamente prescrito e do tempo de trabalho real, os pesquisadores convergem na imagem de que o tempo da atividade do ensino é dual e marcado por ritmos diferentes, se cotejado com outros profissionais do setor público.

Em revisão da literatura produzida sobre a profissão docente na França e na Europa, a análise efetuada aponta para o fato de que o trabalho do professor tem se modificado em termos do conteúdo e da autonomia profissional, em função da avaliação dos sistemas escolares e da política de responsabilização (Maroy, 2006). Para esse autor, a centralização do currículo, a instauração de mecanismos de quase-mercado e a avaliação externa dos estabelecimentos e dos professores afetam tanto os modos de regulação do sistema como o funcionamento das escolas e do trabalho docente (op.cit).

Entre as críticas de inspiração marxista, os autores vêm advertindo para o perigo das reformas estarem contribuindo para a desqualificação dos 
professores, para sua proletarização, pois a natureza do trabalho passa a ser estreitamente controlada e os programas definidos em termos de objetivos, estratégias de ensino, etc. Nessa revisão de bibliografia, nota-se uma censura à pressão crescente que se vem fazendo sobre a performatividade da atividade docente e seus corolários, o estabelecimento de escolas eficazes, os bônus pagos aos professores das classes com alto desempenho (Maroy, 2006).

Todos esses processos acabam por desvalorizar competências pedagógicas profissionais construídas ao longo de trajetórias. Com as políticas de avaliação e responsabilização, os professores cada vez mais têm um sentimento de fragmentação identitária ligado às tensões entre propostas oficiais e suas concepções pessoais. Essa tensão alimenta o que muitos autores denominam desprofissionalização (op.cit).

Estudos recentes vêm mostrando que o próprio clima das escolas tem se modificado, pois as prioridades são fixadas do exterior, passando-se de um engajamento ético e de confiança para um trabalho focado no domínio acadêmico (performático) e não socioeducativo e afetivo (Maroy, 2006).

Todo esse conjunto de mudanças traz um sentimento de mal-estar profissional, pois as condições de trabalho parecem ser mais difíceis. Como saída, alguns estudos insistem sobre a necessidade de desenvolver a formação e o desenvolvimento profissional dos professores para reforçar sua profissionalidade.

Se a análise efetuada está referida à Europa e à França, em pesquisa ${ }^{1}$ realizada, entre 2005 e 2007, com professores de séries iniciais de cinco escolas municipais de alto desempenho na PROVA BRASIL localizadas em

\footnotetext{
1 Trata-se da pesquisa Do estatuto profissional ao exercício do ofício de professores, desenvolvida de 2005 a 2008 , com financiamento do Conselho Nacional de Desenvolvimento Científico e Tecnológico (CNPQ) no Programa de Pós-Graduação em Educação da Pontifícia Universidade Católica do Rio de Janeiro (PUC-Rio). Essa pesquisa foi parte de um Programa História da Profissão Docente no Brasil e em Portugal (acordo CAPES/Coordenação de Aperfeiçoamento de Pessoal de Nível Superior - GRICES/ Gabinete de Relações Internacionais da Ciência e do Ensino Superior de Portugal).
} 
bairros da cidade do Rio de Janeiro, esse sentimento de mal-estar profissional dos professores aflorou nas falas de gestores do nível intermediário do sistema e de diretores de escolas, diante da ampliação da política de ciclos para toda a rede de ensino (Lelis et al., 2009). Para os entrevistados, a resistência dos professores face às reformulações, vistas pelos docentes como um "pacote a mais", tinha como principal argumento o fato do magistério não se sentir preparado para lidar com uma série de orientações que entrava em conflito com a sua formação inicial (op.cit).

\section{Diversificação das funções do professor}

É com o processo de democratização e massificação da escola em um quadro de declínio do Estado Nacional, aceleração de processos supranacionais que assistimos a um sentimento de crise da escola, podendo-se situar essa crise exatamente na sua abertura a novos públicos e nas mudanças nos modos de seleção (Dubet e Martucelli, 1996). Para esses autores, em um quadro de igualdade de oportunidades, a seleção deixou de ser social para passar a ser escolar, ou percebida como tal.

Se, antes, a seleção era anterior à entrada na escola, com a chegada desses novos públicos, a competição deslocou-se para dentro do sistema de ensino e deu origem ao modo de seleção pelo insucesso, pelo baixo desempenho. Ou seja, a democratização do acesso a percursos escolares mais longos traduziu-se não apenas na desvalorização dos diplomas, mas na translação das desigualdades para níveis superiores do sistema escolar, em especial, ensino médio e superior (Canário, 2005). A esses mecanismos internos de seleção escolar, somaram-se às desigualdades fenômenos de segregação espacial urbana com fenômenos de segregação escolar baseados na diferenciação entre estabelecimentos de ensino e em comportamentos de evitamento de certas escolas e suas populações, professores, alunos e suas famílias (op.cit). 
Por essa perspectiva, reconhece-se o estabelecimento de ensino como unidade crucial de gestão do sistema, o que vai se traduzir em políticas de descentralização e autonomia, sendo a regulação feita a posteriori, baseada nos resultados (Canário, 2005). Essa perspectiva apoia-se na ideia de que a escola partilha de um fenômeno de desinstitucionalização, que é indissociável do declínio do Estado-Nação (Dubet, 2002), deixando de ser instituição, uma organização e um modo de socialização (Canário, 2005).

No quadro de um esgotamento do "programa institucional", os atores passam de um desempenho de um papel a um processo de construção da sua experiência escolar, sendo central a construção do sentido do trabalho realizado na escola (Dubet, 2002). Trata-se de perda de legitimidade provocada pela distância cada vez maior entre as expectativas sociais colocadas na escola e as possibilidades de sua concretização (Canário, 2005). Nesse contexto, as diversas manifestações de recusa de aprender por parte dos alunos assumem variadas formas, como o absenteísmo, a indisciplina, a dispersão, o abandono.

Com relação ao professor, o que se observa é que não será mais apenas o estatuto profissional que irá definir o papel a ser desenvolvido. Pesará, e muito, a personalidade do docente. Ainda que estejam presos às regras burocráticas que os enquadram, os professores definem o seu ofício como uma construção individual realizada a partir de elementos esparsos: o respeito ao programa, a preocupação pelas pessoas, a busca dos desempenhos dos alunos e da justiça. (Dubet, 2002, p.16). Trata-se de um profissional que não detém mais com exclusividade as informações. A gestão da classe, a partir de uma autoridade pedagógica, apresenta-se como uma tarefa primordial, visto que os alunos não são mais os mesmos e possuem características socioculturais novas - enquanto sujeitos de direitos.

Mais do que ser um bom professor, o docente tem hoje que construir sua própria legitimidade, motivando a qualquer custo o aluno, con- 
trolando a dispersão da classe, uma vez que a mobilização para os estudos não está mais assegurada, independentemente da qualidade do trabalho do professor.

Isto é, o trabalho é definido por características que não se revelam diretamente na aprendizagem de técnicas e de procedimentos, nem tampouco a partir das funções que lhe são atribuídas pelas agências de formação, associações profissionais e pelo Estado. A complexidade do trabalho é tal que leva o professor a ter que administrar tensões e microconflitos que inexistiam no passado, quando a escola possuía um público homogêneo e sua função era apenas a de transmitir conhecimentos (Dubet, 2002).

Nesse quadro, passam a ser decisivas, para os professores, competências relacionais e emocionais para dar conta da gestão da classe (Barrère, 2002). Ou seja, a mudança do trabalho do professor provocada pelo papel crescente dos meios de comunicação de massa, das tecnologias da comunicação, mas também pela crise dos modelos de autoridade, passou a requerer dos docentes habilidades não regulamentadas pelas burocracias, mas valorizadas social e institucionalmente e que incluem componentes éticos, afetivos e emocionais. A expansão da escola de massa trouxe um público multicultural com modos de socialização familiar muito diversos dos padrões de referência do modo escolar (Maroy, 2006).

Na verdade, o que precisa ser retido é o fato de que as novas culturas juvenis exigem do professor uma implicação pessoal e moral importante, um sentido de responsabilidade grande, pois muitas e contraditórias são as competências exigidas.

Na perspectiva de pensar a construção da profissão docente no Brasil, Oliveira (2010) insiste na ideia de que quanto mais variadas são as funções a que o professor é chamado a responder, mais cresce o sentimento de desprofissionalização, de perda de identidade, na constatação de que ensinar às vezes não é o mais importante (Oliveira, 2010, p. 24). 
Para a autora, situações como essa contribuem para que uma parcela da sociedade passe a suspeitar do professor, como alguém sem a competência esperada e necessária para ensinar. A própria busca permanente de mensuração do desempenho dos alunos acaba levando a um sentimento de que é preciso fiscalizar a escola e o trabalho dos professores (Oliveira, 2010 p.24).

\section{Desenvolvimento profissional do magistério e efetividade do ensino}

Nas últimas décadas, cresceram em importância os estudos e as pesquisas sobre as escolas eficazes, a efetividade do professor. A exigência de uma mão de obra docente de melhor qualidade é claramente e cada vez mais um assunto de Estado e ultrapassa fronteiras nacionais.

Preocupado com o papel da universidade na formação de professores em contexto de busca por maior eficácia por parte do Estado, Claude Lessard identifica três desafios colocados às instituições formadoras. A primeira trata da necessidade da universidade colocar em tensão perspectivas diferenciadas de desenvolvimento profissional dos docentes e da melhoria das escolas. $\mathrm{O}$ segundo desafio diz respeito à necessidade de os professores gerenciarem as políticas de avaliação de resultados. Por fim, o autor adverte sobre o perigo da ênfase excessiva posta nos métodos quantitativos, sem que se pense a problemática dos valores e da ética em pesquisa. Para esse autor, pelo viés das políticas, tenta-se coordenar o conjunto dos atores envolvidos de modo a obter a coerência de suas ações, inserindo-os globalmente na economia do saber, na globalização da concorrência e na ética da responsabilização e do desempenho (Lessard, 2006, p. 204). Recorrendo a Grimmett et al. (2005), que propôs distinguir profissionalização da mão de obra docente da profissionalização do con- 
texto de trabalho, o autor canadense chama a atenção para a importância de duas políticas de Estado: melhoria das escolas e desenvolvimento da mão de obra docente, garantindo-se graus de descentralização combinados com novos modos de regulação.

Nesse quadro, os referenciais de competência que estão no cerne das políticas de profissionalização da mão de obra compõem-se com diferentes epistemologias da prática, diferentes concepções da aprendizagem e do ensino, sejam do tipo aplicacionista ou socioconstrutivista. Esses referenciais contribuem para construir "padrões" de desempenho possíveis de serem mensurados em avaliação do desempenho dos docentes em exercício. O importante não é optar por uma dessas orientações, mas de colocá-las em tensão, tentando conciliar eficácia com reflexividade (Lessard, 2006).

Com relação à avaliação dos resultados da formação, o autor problematiza essa abordagem, interrogando se esse tipo de avaliação conduz a práticas mais eficazes. Para o autor, talvez o cerne da questão esteja não na formação para a eficiência mas o desenvolvimento de competências para o professor compreender o que o torna eficiente, dentro de tal situação, com tal ou qual grupo de alunos (Lessard, 2006 p. 218).

Finalmente, o terceiro desafio é o de pensar a relação entre avaliação de resultados e a ciência. Nessa direção, as políticas do Estado avaliador valorizam os instrumentos de medição quantitativa como indicadores de rendimento do sistema educativo, expressos em testes para medir a aprendizagem dos alunos e a formação de professores. E isso pode acabar por contaminar a pesquisa, facilmente seduzida por verbas importantes que o Estado possa liberar para trabalhos que meçam a eficiência e eficácia dos docentes (op.cit).

O texto traz uma importante contribuição e o faz com relação à importância de políticas de avaliação de professores. Longe de negar o significado de indicadores que devem instruir políticas educacionais com 
vistas a sanar problemas crônicos dos sistemas de ensino (Costa e Koslinski, 2011), Lessard se pergunta se a avaliação de resultados não estaria se reduzindo às proficiências em determinadas áreas de conhecimento, justamente aquelas que se pode medir, à perícia docente à sua eficácia, concebida como valor agregado; e o valor da formação ao seu rendimento (Lessard, 2006, p. 221).

Em direção semelhante, pesquisadores muito recentemente reiteraram a importância dos instrumentos de medição da aprendizagem que permitiram o aprimoramento das estatísticas educacionais e o aprofundamento do diagnóstico da situação da educação brasileira. Mas o fizeram sinalizando para a necessidade de pensarmos os limites que encerram aqueles instrumentos, exatamente pelo risco de redução da concepção de qualidade educacional àquilo que pode ser verificado nas medidas (Carta de Campinas, 2011, p. 2).

Analisando a relação entre pesquisas sobre eficácia escolar e políticas educacionais, algumas críticas foram levantadas sobre a responsabilização das escolas e dos professores pelos governos, sobre a rotulação que se vem fazendo em relação aos estabelecimentos de ensino como únicos agentes de sucesso ou insucesso, sobre a simplificação das listas de fatores importantes associados às escolas eficazes e, por conseguinte, ao desvio de atenção às complexas causalidades associadas ao ensino, e, finalmente, à fragilidade teórica dos estudos sobre eficácia escolar (Goldstein e Woodhouse, 2008).

Mas a preocupação com a profissionalização da mão de obra docente e a efetividade do ensino não é prerrogativa apenas da América do Norte e da Grã-Bretanha. Em texto recém-publicado, são analisadas as concepções de educação e de formação docente esboçadas pela Organização de Cooperação e Desenvolvimento Econômico (OCDE) e suas influências sobre a regulação das políticas de formação do magistério em diferentes contextos. Esse organismo tem sido uma referência para o campo da formação de pro- 
fessores, expressando-se através de documentos, divulgação de pesquisas e também aconselhamento a vários países-membros (Maués, 2011).

Dentre os vários recursos utilizados, está o Programa Internacional para o Acompanhamento das Aquisições dos Alunos (PISA), exame internacional que tem como finalidade construir indicadores para as áreas de Leitura, Matemática e Ciências. Em função dos resultados no exame, a OCDE tem buscado soluções junto aos países participantes, especialmente para a formação de professores. Apoiada em vários documentos, a autora mostra a centralidade da formação de professores para a OCDE e a relação entre educação e capital humano com vistas ao crescimento econômico, redução das desigualdades e promoção individual (Maués, 2011, p. 77).

Em 2002, o organismo deu início a um estudo junto a 25 países sobre políticas de formação docente voltadas para os fatores essenciais que estão em jogo quando se trata de atrair e reter os profissionais de ensino. Esse trabaIho foi concluído em 2005 e resultou em um documento com 270 páginas.

Uma das motivações do interesse da OCDE para com a formação docente está no fato de que, nos próximos anos, um número significativo de docentes irá se aposentar, e a substituição de novos docentes deverá ser feita a partir de um perfil diferente daqueles colegas que estão achegando à idade da aposentadoria. Um quadro apresentado no documento revela que $25 \%$ dos professores dos anos iniciais e $30 \%$ do ensino médio têm mais de 50 anos, chegando a 40\% do corpo docente em alguns países (Maués, 2011). Para esse organismo, algumas preocupações precisam ser consideradas no delineamento das políticas. A primeira delas diz respeito à perda de status do professor, ao sentimento de desvalorização. Faz-se acompanhar de uma preocupação de que as novas gerações de docentes não sejam tão competentes quanto àquela que está se aposentando. Uma outra inquietação relacionada à anterior está dirigida aos professores em início de carreira no sentido de se integrarem à cultura escolar, 
contribuindo assim, de forma efetiva, com os processos de ensino. Uma terceira ordem de preocupação está voltada para o recrutamento, seleção e emprego dos professores. Por último, o documento de 2005 da OCDE fala da sobrecarga de trabalho, do estresse que acaba por comprometer a qualidade do trabalho (op.cit).

No âmbito das políticas de formação, esse organismo estabeleceu as seguintes metas: desenvolvimento de ações relacionadas ao aumento de interesse pela profissão docente, revisão e melhoria da formação docente; busca de estratégias de permanência na profissão e aperfeiçoamento da seleção de novos professores e, paralelamente, melhoria do status e da competitividade dos professores, através do reconhecimento público da profissão (Maués, 2011).

Se o estudo da OCDE revela a importância da questão da formação de professores para os diferentes países, centrais e periféricos, há alguns aspectos que precisam ser considerados. As soluções para os problemas da educação e da formação de professores não podem estar apoiadas apenas na racionalidade técnica. Aspectos históricos, políticos, demográficos de cada país precisam ser levados em consideração na elaboração de políticas educativas. As diferenças entre os sistemas escolares, os graus de democratização do ensino que os países alcançaram são variáveis importantíssimas no desenho das novas orientações educacionais.

Em conferência realizada entre os dias 27 e 28 de setembro de 2007, em Lisboa, sobre o desenvolvimento profissional dos professores para a qualidade e para a equidade, organizada pela Comunidade Europeia, seção portuguesa ${ }^{2}$, o debate foi marcado pela concordância com

2 A partir da conferência que contou com a participação de representantes de 20 países, foi elaborado um documento intitulado Unidos aprendemos. Reforçar a cooperação para a equidade e para a qualidade da Aprendizagem ao longo da vida 2007,com textos de pesquisadores de universidades europeias. 
princípios gerais, mas também houve sérias críticas relativas a algumas questões como a subordinação das políticas educacionais a interesses econômicos; a concepção do professor como executante e as relações entre formação de professores e os processos de aprendizagem dos alunos entre outras (Canário, 2007).

Para esse autor, essa retórica discursiva, a qual estabelece relações lineares entre educação, produtividade e competitividade, empobrece $o$ debate e o pensamento sobre educação, difunde ideias e ilusões totalmente contraditórios face aos dados empíricos pois a escola não cria empregos per si e nem reforça necessariamente a coesão social (Canário, 2007, p. 136). E continua, afirmando que o documento-base da conferência contém um modelo de articulação linear entre racionalidade das políticas educacionais e racionalidade das políticas de formação de professores. É nessa dupla racionalidade que se pensam os processos de mudança das escolas, conduzidos de cima para baixo. Nela, a prática do professor corresponderia a transferir e aplicar aos alunos aquilo que foi ensinado aos professores. Essa função redutora do professor foi muito criticada durante a conferência e contraposta a uma perspectiva que considera o docente como analista simbólico, aquele que exerce sua ação em contextos marcados pela complexidade, incerteza e imprevisibilidade, em que dimensões coletivas e contextuais da aprendizagem profissional têm um peso grande (Canário, 2007, p. 138).

Outra questão considerada séria, presente no documento, e que foi levantada no debate é a análise segmentada que dissocia a discussão das políticas de formação de professores dos problemas relativos à diversidade dos públicos escolares e dos modos como estes se relacionam com a educação escolar. O trabalho do professor não pode ser pensado separadamente do trabalho do aluno. Não é produtivo questionar a formação e o exercício profissional dos professores sem se interrogar o que mudou, como os alunos constroem a sua experiência escolar, qual a relação com o saber, qual o sentido atribuído às vivências escolares (Canário, 2007, p. 139). 


\section{Mal-estar profissional: outros recortes para o aprofundamento da questão}

A partir do levantamento da literatura internacional e nacional sobre a profissão docente, de documentos como os da OCDE e da Conferência da Comunidade Europeia, seção portuguesa, nossa atenção se voltou para análise do trabalho dos professores no contexto brasileiro, no sentido de verificar se questões como a intensificação e complexificação do trabalho docente, a diversificação das funções do professor e o desenvolvimento profissional também assumiam a centralidade posta pela produção acadêmica e por organismos internacionais. A partir de algumas referências de análise, ${ }^{3}$ selecionamos três problemas que se põem hoje ao trabalho dos professores: a sobrecarga de trabalho gerada por um conjunto de fatores, o esgotamento (síndrome de burnout) que vem acometendo cada vez mais essa categoria profissional e as dificuldades de acesso à atualização profissional. São problemas que têm afetado uma parcela do

\footnotetext{
3 Algumas pesquisas serviram para a análise do tema do mal-estar profissional como Professores do Brasil: impasses e perspectivas, coordenadas por Bernadete Gatti e Elba Sá Barreto, publicada em 2009 pela UNESCO; Do estatuto profissional ao exercício do ofício (2005-2008) e Escolas privadas de setores populares: quem são seus professores? (2008-2011), coordenadas por Isabel Lelis, do Programa de Pós-Graduação em Educação da PUC-Rio, com financiamento do Conselho Nacional de Desenvolvimento Científico e Tecnológico (CNPQ) e da Fundação de Amparo à Pesquisa do Estado do Rio de Janeiro (FAPERJ). A primeira pesquisa teve como objetivo a análise do perfil dos professores, e a base de dados foi a Pesquisa Nacional de Amostra por Domicílios (PNAD), por maior aproximação ao número exato dos sujeitos. A segunda investigação teve como foco o perfil de professores das séries iniciais (em um total de 51) de cinco escolas públicas de alto desempenho da cidade do Rio de Janeiro. Através de questionários aplicados aos professores, de entrevistas com lideranças sindicais do SINPRORio (Sindicato dos professores de escolas privadas) e SEPE (Sindicato Estadual dos Profissionais da Educação) e equipes da Secretaria Municipal da Educação do Rio de Janeiro, diretoras das escolas, foi possível verificar as tensões entre o estatuto e o exercício do ofício desse grupo profissional. O terceiro estudo procurou verificar o perfil demográfico, a posição social, a renda, as condições de trabalho, o exercício em sala de aula de 24 professores, lotados em duas escolas que atendem a setores populares, objeto silenciado pela literatura educacional. O questionário, as entrevistas e a observação foram as ferramentas usadas.
} 
magistério da rede pública carioca (e, certamente, de outros municípios e estados do Brasil) e de escolas privadas de setores populares.

De acordo com os dados do PNAD, de um total de professores brasileiros (2.387.086) distribuídos entre a educação infantil, o ensino fundamental e o ensino médio, $81,7 \%$ declararam ter um trabalho só, como docente; outros $16,8 \%$ tinham dois trabalhos, e 1,5\%, três ou mais. A maioria absoluta $(97,7 \%)$ trabalhava como empregado, principalmente no setor público, estando 20,9\% no setor privado (Gatti e Barreto, 2009, p.29).

Quando passamos à jornada de trabalho, indicada ao IBGE pelos professores da educação básica, observamos que tanto homens como mulheres exercem o magistério em torno de 30 horas semanais em sala de aula, ultrapassando em muito essa carga horária se considerarmos o tempo empregado em preparação de aulas, correção de provas, estudos realizados fora do horário escolar e que deveriam ser acrescidos ao tempo do trabalho para melhor dimensionarmos a jornada semanal dos docentes. (Gatti e Barreto, 2009, p.30). Quando comparamos os níveis de ensino, vamos encontrar diferenças, tendo os professores leigos uma média de 20 horas de jornada semanal e os do ensino médio, 32 horas (op.cit.).

Ao compararmos as jornadas masculinas e femininas, verificamos o mesmo número de horas por semana para professores do ensino fundamental com formação em nível superior. Já as professoras das séries iniciais trabalham mais (30 horas) do que as que estão no ensino médio, tendo uma jornada de 24 horas (op.cit.).

Se passamos a comparar professores da rede pública e privada, a tendência é de maior carga horária (30 horas) na primeira em relação à segunda rede. A maior diferença, contudo, está na jornada do ensino médio na rede pública, em torno de 40 horas para 26 horas da rede privada. 
Com relação às condições de trabalho de escolas privadas de setores populares, entrevistas realizadas com dirigentes do SINPRO-Rio ${ }^{4}$ indicam que há um sem-número de professores atuando nesse tipo de instituição, principalmente na zona norte e oeste da cidade, sem contrato de trabalho e, portanto, sem estabilidade de emprego, vivendo a profissão em grau elevado de precarização das relações de trabalho, o que significa dizer flexibilização e desregulamentação da legislação trabalhista (Oliveira, 2004). Sob condições hostis, os docentes trabalham como horistas, revelando a ausência de um plano de carreira em termos de promoção por mérito ou tempo de serviço. Essa situação tem provocado uma rotatividade de professores no interior desse tipo de rede de ensino. Para um dos entrevistados, falta uma maior regulamentação sobre o exercício da profissão, sendo frágil o controle do poder público municipal e/ou estadual sobre o funcionamento dessas escolas (Lelis e Xavier, 2009).

Mas há ainda outros desafios a serem enfrentados pelo magistério da rede pública do Rio de Janeiro. Nas falas de membros da diretoria do SEPE, dificuldades são trazidas como a falta de motivação profissional dos professores, a existência de planos de carreira diferenciados (são três tipos de carga horária no sistema estadual de ensino), ${ }^{5}$ aparecimento de

\footnotetext{
4 As entrevistas realizadas em 2007 com membros da diretoria do Sindicato Estadual de profissionais da Educação (SEPE) e do Sindicato dos Professores do Rio de Janeiro (SINPRO-Rio), em número de 10 tiveram como objetivo verificar as condições de trabalho, as necessidades e desafios desse grupo profissional, as diferenças entre as duas redes de ensino. O SEPE é o sindicato voltado para o magistério da rede pública, municipal e estadual. O SINPRO-Rio é o sindicato que atende a professores da rede privada da cidade do Rio de Janeiro.

5 Para uma professora que ocupa uma das diretorias do SEPE, há três tipos de professores na rede estadual. O professor que possui uma carga horária de 40 horas semanais, oriundo do Governo Brizola, do antigo concurso para o CIEP (Centro Integrado de Educação Pública). Para a entrevistada, dez mil professores encontram-se nessa situação hoje. Há o Professor com uma carga horária de 16 horas, doze em sala de aula e quatro horas em atividade extraclasse e o Professor que tem uma carga horária de 30 horas semanais, originário do penúltimo concurso. Há ainda uma gratificação GLT - gratificação por lotação prioritária, para aqueles docentes que trabalham em áreas difíceis.
} 
um conjunto de doenças e, por consequência, aumento de licenças como nunca se viu antes no Rio de Janeiro ${ }^{6}$. Mais do que evasão ou abandono dos docentes, o que se observa é um vaivém entre redes de ensino (municipais, estaduais) na busca por melhores salários e condições de trabalho. Para um dirigente do SEPE, os professores não abandonam o magistério por falta de vocação, mas sim quando percebem que o trabalho deixou de ter relação com as necessidades, expectativas e interesses dos docentes. Nos questionários aplicados em cinco escolas municipais do Rio de Janeiro, os professores apontaram ainda para a escassez de recursos materiais, para a falta de apoio técnico pedagógico nas escolas, para o número excessivo de alunos por turma e a falta de incentivo ao aprimoramento profissional. A esses fatores, devem-se acrescentar o nível de violência em determinados locais e a falta de segurança nos estabelecimentos de ensino próximos às zonas de tráfico de drogas (Lelis e Xavier, 2010).

Todo esse quadro ajuda a entender por que tanto tem se discutido a proletarização do magistério, caracterizada pela perda de controle do trabalhador (professor) do seu processo de trabalho, contrapondo-se à profissionalização como condição de preservação e garantia de um estatuto profissional que leve em conta a autorregulação, a competência específica, rendimentos, licença para atuação, vantagens e benefícios próprios, independência (Oliveira, 2004, p. 1138).

É significativo o depoimento de um entrevistado ao falar da ampliação das funções da escola e das consequências desse processo para a organização do trabalho docente. A descrição do aumento das demandas

6 O Sindicato Estadual dos Profissionais de Ensino (SEPE) encomendou à Fundação Oswaldo Cruz (FIOCRUZ) uma pesquisa sobre a saúde dos professores na cidade e estado do Rio de Janeiro. Um dado significativo que apareceu foi o fato de um percentual expressivo de docentes de séries iniciais estar se afastando precocemente da profissão, em torno do décimo quarto ano em função da síndrome de burnout, traduzida por esgotamento físico e emocional. 
que vêm se apresentando aos professores pode ser interpretada como um dos aspectos da perda de controle sobre o seu próprio trabalho:

...veja a situação de quem recebe uma criança de 5, 6, 7 anos em uma zona de enfrentamento de violência, zona de carências culturais, de falta de assistência social. São crianças que demandam da professora de primeira a quarta série uma maior exigência de atendimento. A criança não vai à terapia, não tem um pediatra que a acompanhe... não tem uma família que dê uma assistência completa. Então esta professora acaba tendo muitas funções dentro da escola. Muitas vezes trabalha sem auxiliar e com turmas muito grandes... (dirigente sindical do SEPE)

Os variados papéis que a escola é chamada a assumir colocam para o professor exigências que estão além de sua formação, como o de se tornar enfermeiro, psicólogo, assistente social. Tais demandas contribuem para um sentimento de perda de identidade profissional, de constatação de que ensinar, às vezes, não é o mais importante, recorrendo-se frequentemente aos atributos pessoais, isto é, aos recursos e/ou estratégias que cada professor, individualmente, é capaz de mobilizar diante de funções e atribuições para as quais ele não foi preparado para enfrentar em seu processo de formação inicial ou continuada (Oliveira, 2004).

Mas as pesquisas também têm evidenciado outros problemas. Entre os principais conflitos enfrentados pelos docentes na gestão da classe, estão a indisciplina, a dispersão, a dificuldade de envolvimento das famílias com a escolarização dos seus filhos. Ou seja, dificuldades que remetem, em última análise, às transformações sociais, como a incorporação crescente da mulher ao mercado de trabalho, às mudanças dos modelos de autoridade, às novas configurações familiares que colocam o professor em um quadro de relações de grande complexidade. Entre os desafios colocados, ainda está a precariedade de condições para atualização profissional. Gestoras entrevistadas foram unânimes em reconhecer que, apesar de acreditarem 
na importância da atualização dos professores, não podem dispensá-los das aulas por não terem como substituí-los (Lelis et al., 2009).

Considerando que a sobrecarga de trabalho, a diversificação de tarefas do professor, as dificuldades de formação continuada são entraves à profissionalização do magistério e que esses problemas são realidade também em outros países, Nóvoa (1992) sugere que os professores definam um território ou campo de ação como forma de controle da profissão, em sintonia com uma política de melhoria do funcionamento das escolas, também destacada antes por Lessard (2006). No nosso caso, há uma série de condições básicas que precisam ser equacionadas, como a institucionalização da formação continuada, salários dignos, serviços de apoio ao professor (supervisão pedagógica), combinados na formulação de políticas públicas. Para Nóvoa, uma outra alternativa é a de que:

se caminhe para a promoção de espaços entre pares, de trocas de partilhas como possibilidade de potencializar os princípios do coletivo e da colegialidade na cultura profissional dos professores (Nóvoa, 2008, p. 231).

Essa alternativa se apresenta como uma forma de buscar o fortalecimento do professor, com a consequente valorização profissional, ao lado de estratégias de luta por condições dignas de trabalho do magistério, que os sindicatos já vêm fazendo. Ao lado desta questão, há também a necessidade de reorganização do trabalho escolar, reservando aos professores tempo maior para a reflexão sobre a sua prática e o intercâmbio de ideias (Lelis e Xavier, 2010). Por esse caminho, haverá espaço para o registro de práticas pedagógicas significativas, de preservação do patrimônio pedagógico produzido em cada escola, de modo que a experiência acumulada pelo trabalho de gerações de professores possa ser socializada, apropriada e ressignificada por todos aqueles que desempenham o ofício de professor. 


\section{Referências}

BARRÈRE, Anne A. Les enseignants au travail. Paris: L'Hartmattan, 2002.

CANÁRIO, Rui. O que é a Escola? Um "olhar" sociológico. Porto: Porto Editora, 2005.

CANÁRIO, Rui. Formação e desenvolvimento profissional dos professores In: Portugal 2007 - Conferência Desenvolvimento profissional de professores para a qualidade e para a equidade da Aprendizagem ao longo da vida, Lisboa, 2007.

CARTA DE CAMPINAS. Disponível em: http://www.jornaldaciencia.org.br/index2.jsp

COSTA, Marcio; KOSLINSKI, Mariane. Quase-Mercado Oculto: disputa por escolas "comuns" no Rio de Janeiro. Cadernos de Pesquisa. v.41. n.142, p 246-266, jan/abr 2011.

DUBET, Françoiś; MARTUCELLI, Danilo. À I’école. Sociologie de I’expérience scolaire. Paris: Édition du Seuil, 1996.

DUBET, François. Le Déclin de L'institution. Paris: Édition du Seuil, 2002.

FORMOSINHO, João. Ser professor na escola de massa In: FORMOSINHO, J. (Org.) Formação de professores. Aprendizagem profissional e ação docente. Porto: Porto Editora Ltda, 2009.

GATTI, Bernadete; BARRETO, Elba S. Professores do Brasil: impasses e desafios. Brasília: UNESCO, 2009.

GOLDSTEIN, Harvey; WOODHOUSE, Goeffrey. Pesquisa sobre eficácia escolar e políticas educacionais. In BROOKE, N.; SOARES, J. F. Pesquisa em eficácia escolar. Origem e trajetórias. Belo Horizonte: Editora UFMG, 2008.

LELIS, Isabel; IORIO, Angela Cristina; MESQUITA, Silvana; NASCIMENTO, Maria das Graças. O trabalho docente: a tensão entre intensificação e o bem-estar profissional In: LELIS, I.; NASCIMENTO, M. G. (Org). O trabalho docente no século XXI: quais perspectivas? Rio de Janeiro: Editora Forma e Ação, 2009.

LELIS, Isabel; XAVIER, Libania. O ofício docente na voz de suas lideranças sindicais. In: LELIS, I.; NASCIMENTO, M. G. (Org). O trabalho docente no século XXI: quais perspectivas? Rio de Janeiro: Editora Forma e Ação, 2009.

LESSARD, Claude. A universidade e a formação profissional dos docentes: novos questionamentos. Educação e Sociedade, vol. 27, n.94, p.201-227, jan./abr. 2006.

MAROY, Christian. Note de synthèse. Les evolutions du travail enseignant en France et en Europe: facteurs de changement, incidances et resistances dans I' 
enseignement secondaire. Revue Française de Pédagogie, n.155, p.111-142, avril-mai-juin 2006.

MAUÉS, Oldemária. C. A política da OCDE para a educação e a formação docente. A nova regulação? Educação, v. 34, n.1, p.75-85, jan./abr. 2011.

NÓVOA, Antonio. Para uma análise das organizações escolares. In: NÓVOA, A. (Org.). As organizações escolares em análise. Lisboa: Publicações Dom Quixote, 1992.

NÓVOA, Antonio. O regresso dos professores In: Portugal 2007 - Conferência Desenvolvimento profissional de professores para a qualidade e para a equidade da Aprendizagem ao longo da vida. Lisboa, 2007.

NÓVOA, Antonio. Os professores e o novo espaço público da educação. In: TARDIF, Maurice; LESSARD, Claude (Org.). O ofício de professor: história, perspectivas e desafios internacionais. Petrópolis: Vozes, 2008.

OLIVEIRA, Dalila A. A reestruturação do trabalho docente: precarização e flexibilização. Educação e Sociedade. vol. 26, n.89, p. 1127-1144, set/dez 2004.

OLIVEIRA, Dalila. A. Os trabalhadores da educação e a construção política da profissão docente no Brasil. Educar em Revista, especial 1, p.17-35, 2010.

TARDIF, Maurice; LESSARD, Claude. Le travail enseignant au quotidian: experience, interactions humaines, et dilemmes professionnels. Bruxelles: De Boeck, 1999.

Recebido em: 09/08/2011

Aceite final: 21/10/2011 